\title{
Application of a Reliable LC-MS/MS Method for Determination of Rizatriptan in Healthy Subject Samples: Demonstration of Assay Reproducibility by Incurred Sample Reanalysis
}

\author{
Dinesh S. Patel, ${ }^{1,2}$ Naveen Sharma, ${ }^{2}$ Mukesh C. Patel, ${ }^{1}$ Bhavin N. Patel, ${ }^{2,3}$ \\ Pranav S. Shrivastav, ${ }^{3}$ and Mallika Sanyal ${ }^{4}$ \\ ${ }^{1}$ Department of Chemistry, Pramukh Swami Science \& H. D. Patel Arts College, Sarva Vidyalaya Campus, \\ Kadi 382 715, Gujarat, India \\ ${ }^{2}$ Bioanalytical Laboratory, Cliantha Research Ltd., Bodakdev, Ahmedabad 380054, Gujarat, India \\ ${ }^{3}$ Department of Chemistry, School of Sciences, Gujarat University, Navrangpura, Ahmedabad 380009, Gujarat, India \\ ${ }^{4}$ Department of Chemistry, St. Xavier's College, Navrangpura, Ahmedabad 380009, Gujarat, India
}

Correspondence should be addressed to Bhavin N. Patel, bhavinpatel27@rediffmail.com

Received 7 October 2012; Accepted 29 October 2012

Academic Editors: C. Y. Choo and A. Namera

Copyright (C) 2012 Dinesh S. Patel et al. This is an open access article distributed under the Creative Commons Attribution License, which permits unrestricted use, distribution, and reproduction in any medium, provided the original work is properly cited.

\begin{abstract}
A reliable, rapid, and selective liquid chromatography-tandem mass spectrometry (LC-MS/MS) assay has been proposed for the determination of rizatriptan in human plasma using sumatriptan as internal standard (IS). The analyte and IS were extracted from $300 \mu \mathrm{L}$ human plasma via liquid-liquid extraction and the chromatography was achieved on Hypurity C18 $(50 \mathrm{~mm} \times 4.6 \mathrm{~mm}$, $5 \mu \mathrm{m})$ column under isocratic conditions. Detection of rizatriptan and IS was done by tandem mass spectrometry, operating in positive ionization and multiple-reaction monitoring mode. The limit of detection and lower limit of quantitation of the method were 0.04 and $0.20 \mathrm{ng} / \mathrm{mL}$, respectively, with a linear dynamic range of $0.20-60.0 \mathrm{ng} / \mathrm{mL}$. The intrabatch and interbatch precision ( $\% \mathrm{CV}$ ) was $\leq 8.4 \%$ while the mean extraction recovery was $>78 \%$ across quality control levels. Bench top stability, freeze and thaw stability, processed sample stability, and long-term stability in plasma were evaluated at two quality control levels. It was successfully applied to a bioequivalence study of $10 \mathrm{mg}$ rizatriptan orally disintegrating tablet formulation in 40 and 32 healthy Indian male subjects under fasting and fed conditions, respectively. The reproducibility in the measurement of study data was demonstrated by reanalysis of 254 incurred samples.
\end{abstract}

\section{Introduction}

Rizatriptan [RIZ, N,N-dimethyl-2-\{5-(1H-1,2,4-triazol-1ylmethyl)-1H-indol-3-yl $\}$ ethanamin e] is a potent and selective 5-hydroxytriptamine 1B/1D (5-HT 1B/1D) agonist with a rapid onset of action, used for the acute treatment of migraine headache $[1,2]$. The apparent mechanism of action of RIZ is done through activation of postsynaptic 5-HT $1 \mathrm{~B}$ receptors within cerebral and dural vessel walls, causing vasoconstriction and inhibition of trigeminal perivascular nerve terminals $[3,4]$. RIZ belongs to the second generation antimigraine drugs and is approved for the treatment of migraine at dose strength of 10 and $5 \mathrm{mg}$ [5]. RIZ is completely absorbed after oral administration and shows mean oral bioavailability of $\sim 45 \%$. It undergoes extensive first-pass metabolism via monoamine oxidase-A and the mean plasma concentrations are reached in approximately 1 to $1.5 \mathrm{~h}$. The half-life of RIZ in plasma is $\sim 2 \mathrm{~h}$ and about $14 \%$ of an oral dose is eliminated unchanged in the urine. Approximately $50-60 \%$ of the administered dose is eliminated in the urine as the inactive indole-acetic acid metabolite. Although several minor metabolites have been identified, the $N$-monodesmethyl metabolite is pharmacologically active. As the plasma concentration of this metabolite is about $14 \%$ of the parent compound, it does not significantly contribute to the pharmacodynamic activity of RIZ [3, 6-8]. 
Several methods are reported for determination of RIZ in different biological matrices, either alone [9-14] or in combination with other triptans $[15,16]$. RIZ has been determined in dog plasma [9], urine [10], human serum [16], and human plasma [10-15] mainly by LC-MS except [11]. Two highly sensitive methods $(0.05 \mathrm{ng} / \mathrm{mL})$ have been described by Chen et al. [12] and Guo et al. [13], employing $100 \mu \mathrm{L}$ and $500 \mu \mathrm{L}$ human plasma, respectively, for processing. A method for the simultaneous determination of rizatriptan, zolmitriptan, naratriptan, and sumatriptan in human serum has been proposed [16]. The linear calibration curves were established from 1 to $100 \mathrm{ng} / \mathrm{mL}$ and the mechanism of formation of collision-induced dissociation products for all the triptans was proposed. Recently, Mogili et al. [14] have developed a sensitive $(0.1 \mathrm{ng} / \mathrm{mL})$ and rapid $(3.0 \mathrm{~min})$ isotope dilution LC-MS/MS method for quantitative analysis of RIZ in human plasma.

In the present study a sensitive, selective, rugged, and rapid LC-MS/MS method has been proposed for the determination of RIZ in very small human plasma sample. The method is extensively validated as per the United States Food and Drug Administration (USFDA) guidelines and is adequately sensitive for routine subject sample analysis. The method requires only $300 \mu \mathrm{L}$ human plasma for liquid-liquid extraction (LLE), minimum usage of organic solvents, and demonstrates excellent performance in terms of ruggedness and efficiency (3.0 min per sample). The dynamic linear range was validated from 0.2 to $60 \mathrm{ng} / \mathrm{mL}$. The method is selective in presence of naratriptan, zolmitriptan, and other commonly used medications by healthy subjects. Ion suppression/enhancement was studied by postcolumn infusion of analyte and postextraction spiking technique. The proposed method has been successfully applied to a bioequivalence study of $10 \mathrm{mg}$ rizatriptan orally disintegrating tablet formulation in 40 and 32 healthy Indian subjects under fasting and fed conditions, respectively. The authenticity in the measurement of study data is demonstrated through reanalysis of 254 incurred samples.

\section{Experimental}

2.1. Chemicals and Materials. Reference standard material of rizatriptan benzoate $(99.1 \%)$ was procured from Varda Biotech (Mumbai, India), while sumatriptan succinate (IS, 99.1\%) was a USP reference standard (Rockville, MD 20852, USA). HPLC grade methanol, analytical grade reagent ammonium solution (30.0\%), and diethyl ether were obtained from S.D. Fine Chemicals Ltd. (Mumbai, India) and ammonium salt of trifluoroacetic acid (ATFA, 98\%) was procured from Acros Organics (NJ, USA). Water used for LC-MS/MS was prepared using Milli Q water purification system from Millipore (Bangalore, India). Control buffered ( $\mathrm{K}_{3}$ EDTA) human plasma was obtained from Clinical Department, Cliantha Research India Limited (Ahmedabad, India), and was stored at $-20^{\circ} \mathrm{C}$.

2.2. LC-MS/MS Instrumentation and Conditions. A Shimadzu liquid chromatography system (Kyoto, Japan) and
Hypurity C18 $(50 \mathrm{~mm} \times 4.6 \mathrm{~mm}, 5.0 \mu \mathrm{m})$ column from Thermo Scientific (NJ, USA) were used in the study. The mobile phase consisted of methanol:deionized water: 1.0 M ATFA solution $(60: 40: 0.1, v / v / v)$. The autosampler temperature was maintained at $4^{\circ} \mathrm{C}$ and the flow rate was set at $0.35 \mathrm{~mL} / \mathrm{min}$ for isocratic conditions. Ionization and detection of analyte and IS were performed on a triple quadrupole mass spectrometer, API-3000 equipped with Turbo Ion spray, from MDS SCIEX (Toronto, Canada) operating in the Positive ion mode. Quantitation was done using MRM mode to monitor protonated precursor $\rightarrow$ product ion transition of $m / z 270.1 \rightarrow 201.2$ for RIZ and $296.1 \rightarrow 58.1$ for IS. All the parameters of LC and MS were controlled by Analyst software version 1.4.2.

The source-dependant parameters maintained for RIZ and IS were Gas 1(Nebulizer gas): 14 psi, ion spray voltage (ISV): $2500 \mathrm{~V}$, turboheater temperature (TEM): $550^{\circ} \mathrm{C}$, entrance potential (EP): $10 \mathrm{~V}$, collision activation dissociation (CAD): 3 psi, curtain gas (CUR): 11 psi. The compounddependent parameters like declustering potential (DP), focusing potential (FP), collision energy (CE), and cell exit potential (CXP) were optimized at 22, 130, 25, and $14 \mathrm{~V}$ for RIZ and 22, 130, 27, and $14 \mathrm{~V}$ for IS, respectively. Quadrupole 1 and 3 were maintained at unit resolution. A dwell time of $400 \mathrm{~ms}$ was set for both RIZ and IS, respectively.

2.3. Preparation of Standard Stock and Plasma Samples. The standard stock solution of RIZ $(100 \mu \mathrm{g} / \mathrm{mL})$ was prepared by dissolving requisite amount of rizatriptan benzoate in methanol. Its intermediate solution $(1200 \mathrm{ng} / \mathrm{mL})$ was prepared in methanol-deionized water $(50: 50, v / v)$. The IS stock solution of $100 \mu \mathrm{g} / \mathrm{mL}$ was prepared by dissolving requisite amount of sumatriptan succinate in methanol, while its working solution $(100.0 \mathrm{ng} / \mathrm{mL})$ was prepared using the stock solution in deionized water. All the above solutions were stored at $4^{\circ} \mathrm{C}$ until use. The calibration standards (CSs) at 0.20, 0.40, 1.00, 3.00, 7.50, 15.00, 30.00, 50.00 , and $60.00 \mathrm{ng} / \mathrm{mL}$ concentrations and quality control (QC) samples (LLOQ QC $(0.20 \mathrm{ng} / \mathrm{mL})$, lower limit of quantitation quality control; LQC $(0.60 \mathrm{ng} / \mathrm{mL})$, low-quality control; MQC-2 (5.00 ng/mL) and MQC-1 (24.00 ng/mL), medium quality control; HQC $(45.00 \mathrm{ng} / \mathrm{mL})$, high-quality control; ULOQ QC (60.00 ng/mL), upper limit of quantitation quality control) were prepared by spiking blank plasma with respective working solutions (5\% of total volume of plasma). The spiked plasma samples at all the levels were stored at $-20^{\circ} \mathrm{C}$ for validation and subject sample analysis.

2.4. Protocol for Sample Preparation. Prior to analysis, spiked plasma samples were thawed and allowed to equilibrate at room temperature. The samples were adequately vortexed and aliquots of $300 \mu \mathrm{L}$ plasma solution containing $15 \mu \mathrm{L}$ of working solution of RIZ and $285 \mu \mathrm{L}$ blank plasma were transferred into screw cap tubes. $15 \mu \mathrm{L}$ of deionized water (for CS and QC samples) $/ 15 \mu \mathrm{L}$ of $50 \%$ methanol-water solution (for study samples) was added and vortexed to mix. Further, $100 \mu \mathrm{L}$ working solution of IS $(100 \mathrm{ng} / \mathrm{mL})$ and $100 \mu \mathrm{L} 4.5 \mathrm{M} \mathrm{NH}_{4} \mathrm{OH}$ solution was added and vortexed 
again. Further, $4.0 \mathrm{~mL}$ of diethyl ether was added and the mixture was shaken for $10 \mathrm{~min}$ at $150 \mathrm{rpm}$. The samples were centrifuged for $5 \mathrm{~min}$ at $1811 \times \mathrm{g}$ and the organic layer was transferred to correspondingly labeled tubes after freezing the aqueous layer in dry ice bath. The organic layer was evaporated to dryness under a gentle stream of nitrogen $(15 \mathrm{psi})$ at $40^{\circ} \mathrm{C}$. The residue was taken up in $300 \mu \mathrm{L}$ of mobile phase and $5.0 \mu \mathrm{L}$ was used for injection in LCMS/MS.

\subsection{Methodology for Validation of the Method. A thorough} and complete method validation of RIZ in human plasma was done following the USFDA guidelines [17].

Test for selectivity was carried out in 12 different lots of blank human plasma including haemolysed and lipemic plasma collected with $\mathrm{K}_{3}$ EDTA as an anticoagulant. From each of these 12 different lots, two replicates each of $285 \mu \mathrm{L}$ were spiked with $15 \mu \mathrm{L}$ of methanol-deionized water $(50: 50$, $v / v$ ). In the first set, the double blank plasma (without analyte and IS) was directly injected after extraction, while the other set was spiked with only IS before extraction. Further, one system suitability sample (SSS) at CS-2 $(0.40 \mathrm{ng} / \mathrm{mL})$ concentration and two replicates of LLOQ concentration (CS-1) were prepared by spiking $285 \mu \mathrm{L}$ blank human plasma with $15 \mu \mathrm{L}$ of respective working aqueous standards of RIZ. The acceptance criterion requires that at least $90 \%$ of selectivity samples should be free from any interference at the retention time of analyte and IS.

The potential interferences from the common drugs were determined. These included acetaminophen, aspirin, caffeine, cetirizine, chlorpheniramine maleate, ibuprofen, and pseudoephedrine. Additionally, two triptans, namely, naratriptan and zolmitriptan, were studied for ionization (ion suppression/enhancement), analytical recovery (precision and accuracy), and chromatographic interference (interference with MRM of analyte and IS). Their stock solutions $(100.0 \mu \mathrm{g} / \mathrm{mL})$ were prepared by dissolving requisite amount in methanol. Further, working solutions $(20.0 \mu \mathrm{g} / \mathrm{mL})$ were prepared in methanol-deionized water $(50: 50, v / v)$ solution, spiked in plasma, and analyzed under the same conditions at LQC and HQC levels in triplicate. These sets were processed along with freshly prepared calibration curve standards (CS) and two sets (8 samples) of qualifying QC samples (HQC, MQC-1, MQC-2, and LQC). As per the acceptance criteria, the $\%$ accuracy should be within 85 to $115 \%$. The MRM transitions in the positive ionization mode for naratriptan (336/98) and zolmitriptan (288/243) were studied.

Carryover experiment was performed to verify any carryover of analyte, which may reflect in subsequent runs. The design of the study is comprised of the following sequence of injections, that is, double blank plasma sample $\rightarrow$ two samples of LLOQ $\rightarrow$ double blank plasma $\rightarrow$ ULOQ sample $\rightarrow$ double blank plasma to check for any interference due to carry over.

The linearity of the method was determined by analysis of five calibration curves containing nine nonzero concentrations. The area ratio response for RIZ/IS obtained from multiple reaction monitoring was used for regression analysis. Each calibration curve was analyzed individually by using least square weighted $\left(1 / x^{2}\right)$ linear regression. The lowest standard on the calibration curve was accepted as the LLOQ, if the analyte response was at least ten times more than that of drug-free (blank) extracted plasma.

Intra-batch and inter-batch (on three consecutive validation days) accuracy and precision were evaluated at six QC levels (LLOQ QC, LQC, MQC-2, MQC-1, HQC, and ULOQ $\mathrm{QC})$ in six replicates for RIZ. The deviation (\%CV) at each concentration level from the nominal concentration was expected to be within $\pm 15 \%$. Similarly, the mean accuracy should not vary by $\pm 15 \%$ except for the LLOQ where it can be $\pm 20 \%$ of the nominal concentration. Reinjection reproducibility was performed by reinjecting one validation batch.

The relative recovery, matrix effect, and process efficiency were evaluated as reported previously [18] at HQC, MQC-1, MQC-2, and LQC levels in six replicates. Relative recovery (RE) was calculated by comparing the mean area response of samples spiked before extraction to that of samples spiked after extraction at each QC level. The recovery of IS was similarly estimated. Absolute matrix effect (ME) was assessed by comparing the mean area response of samples spiked after extraction with the mean area response of neat standard solutions prepared in mobile phase. The overall "process efficiency" $(\% \mathrm{PE})$ was calculated as $(\mathrm{ME} \times \mathrm{RE}) / 100$. The relative matrix effect on analyte quantification was also checked in eight different batches/lots of $\mathrm{K}_{3}$ EDTA plasma including haemolysed and lipemic plasma samples at LQC and HQC levels. The deviation of the standards and QCs should not be more than $\pm 15 \%$.

Matrix ion suppression effects on the MRM LC-MS/MS sensitivity were evaluated by the postcolumn analyte infusion experiment [19]. A standard solution containing $45.0 \mathrm{ng} / \mathrm{mL}$ of RIZ and $100 \mathrm{ng} / \mathrm{mL}$ of IS in mobile phase was infused postcolumn via a " $\mathrm{T}$ " connector into the mobile phase at $5.0 \mu \mathrm{L} / \mathrm{min}$ employing Harvard infusion pump. Aliquots of $5.0 \mu \mathrm{L}$ of extracted ULOQ sample and double blank plasma sample were then injected and MRM LC-MS/MS chromatograms were acquired for RIZ and IS.

All stability results were evaluated by measuring the area ratio response (RIZ/IS) of stability samples against freshly prepared comparison standards at LQC and HQC levels. Stock solutions of RIZ and IS were checked for short-term stability at room temperature and long-term stability at $4^{\circ} \mathrm{C}$. The solutions were considered stable if the deviation from nominal value was within $\pm 10.0 \%$. Bench top stability, processed sample stability at room temperature and at refrigerated temperature $\left(4^{\circ} \mathrm{C}\right)$, freeze thaw stability, and long-term stability at $-20^{\circ} \mathrm{C}$ were performed at LQC and HQC levels using six replicates at each level. To meet the acceptance criteria the $\% \mathrm{CV}$ and $\%$ accuracy should be within $\pm 15 \%$.

Dilution integrity experiment was carried out at 5 times the ULOQ concentration $(300 \mathrm{ng} / \mathrm{mL})$ and at HQC level for RIZ. Six replicate samples each of $1 / 10$ of $5 \times$ ULOQ $(30.0 \mathrm{ng} / \mathrm{mL})$ and $1 / 10$ of HQC $(4.50 \mathrm{ng} / \mathrm{mL})$ concentration were prepared and their concentrations were calculated, by applying the dilution factor of 10 against the freshly prepared calibration curve for RIZ. 
2.6. Bioequivalence Study and Incurred Sample Reanalysis. The bioequivalence study was conducted with a single oral dose of test ( $10 \mathrm{mg}$ rizatriptan benzoate orally disintegrating tablets from a generic company) and a reference (MAXALTMLT, $10 \mathrm{mg}$ rizatriptan benzoate orally disintegrating tablets from Merck \& Co. Inc, Whitehouse station, NJ 08889, USA) formulation in 40 and 32 healthy Indian subjects under fasting and fed conditions, respectively. All the subjects were informed of the aim and risk involved in the study and written consent was obtained. The inclusion criteria for volunteer selection were based on the age (18-45 years), body mass index (between 18.5 and $24.9 \mathrm{~kg} /$ height $^{2}$ ), general physical examination, electrocardiogram, and laboratory tests like hematology, blood chemistry, urine examination, and immunological tests. The work was approved and subjected to review by an Institutional Ethics Committee. The procedures followed while dealing with human subjects were based on International Conference on Harmonization, E6 Good Clinical Practice (ICH, E6 GCP) guidelines [20]. The subjects for study were fasted $10 \mathrm{~h}$ before administration of the drug formulation. Further, under fed conditions the subjects were given high fat and high calorie breakfast (consisting of $200 \mathrm{~mL}$ milk with $16 \mathrm{gm}$ sugar, 80 gm of black gram, two slices of bread with butter, and two cheese cutlets, total 969 calories) $30 \mathrm{~min}$ prior to giving the drug under investigation. Blood samples were collected in vacutainers containing $\mathrm{K}_{3}$ EDTA anticoagulant before $(0.0)$ and at 0.167 , $0.333,0.5,0.667,0.833,1.0,1.25,1.5,1.75,2.0,2.333,2.667$, $3.0,3.5,4.0,4.5,5.0,6.0,8.0,10.0,12.0,14.0,16.0$, and $24.0 \mathrm{~h}$ of administration of drug for fasting study and before $(0.0)$ and at $0.25,0.5,0.75,1.0,1.25,1.5,1.75,2.0,2.25$, $2.5,2.75,3.0,3.5,4.0,4.5,5.0,6.0,8.0,10.0,12.0,14.0,16.0$, and $24.0 \mathrm{~h}$ of administration of drug for fed study. Blood samples were centrifuged at $1811 \times \mathrm{g}$ at $4^{\circ} \mathrm{C}$ for $15 \mathrm{~min}$ and plasma was separated, stored at $-20^{\circ} \mathrm{C}$ until use. The pharmacokinetic parameters of RIZ were estimated by noncompartmental model using WinNonlin software version 5.2.1 (Pharsight Corporation, Sunnyvale, CA, USA). An incurred sample reanalysis (ISR) was also conducted by computerized random selection of 254 subject samples near $C_{\max }$ and the elimination phase. The results obtained were compared with the data obtained earlier for the same sample using the same procedure. The percent change in the value should not be more than $\pm 20 \%[21]$ :

$$
\% \text { Change }=\frac{\text { Repeat value }- \text { Initial value }}{\text { Mean of repeat and initial values }} \times 100
$$

\section{Results and Discussion}

3.1. Method Development. The method development was initiated to realize a rugged, selective, and high throughput LC-ESI-MS/MS method to quantify RIZ in human plasma. The tuning of MS parameters was carried out in positive ionization mode for RIZ and IS using $500.0 \mathrm{ng} / \mathrm{mL}$ tuning solution in electrospray ionization source (ESI). The analyte and IS gave predominant singly charged protonated precursor $[\mathrm{M}+\mathrm{H}]^{+}$ions at $m / z$ of 270.1 and 296.1 for RIZ and IS, respectively, in Q1 full scan spectra. Fragmentation was initiated using sufficient nitrogen for CAD and by applying 25.0 V collision energy to break the precursor ion for RIZ. In the product ion mass spectrum of RIZ, the most abundant ion was observed at $\mathrm{m} / \mathrm{z} 201.2$, due to the loss of triazole moiety from the protonated precursor ion (Figure 1(a)). The other product ions at $m / z 158.1$ with a lesser intensity can be attributed to a further loss of dimethylamine from the molecular ion by alpha cleavage. The major product ion of sumatriptan (IS) in Q3 mass spectra was observed at $\mathrm{m} / \mathrm{z}$ 58.1 by applying $27.0 \mathrm{~V}$ collision energy (Figure $1(\mathrm{~b})$ ). This can be ascribed to the formation of $\left[\mathrm{H}_{2} \mathrm{C}={ }^{+} \mathrm{N}\left(\mathrm{CH}_{3}\right)_{2}\right]$ fragment ion. The other two fragments corresponding to $\mathrm{m} / \mathrm{z}$ of 251.2 and $\mathrm{m} / \mathrm{z}$ of 201.1 were due to the elimination of dimethylamine and $\mathrm{CH}_{3} \mathrm{NHSO}_{2} \mathrm{H}$, respectively, from the precursor ion. To attain an ideal Taylor cone and a better impact on spectral response, an optimum potential of $2500 \mathrm{~V}$ was kept which gave consistent and stable signal. Fine tuning of nebulizer gas and CAD gas was done to get a consistent and stable response. A dwell time of $300 \mathrm{~ms}$ was adequate and no cross talk was observed between the MRMs of analyte and IS.

The chromatographic conditions were suitably optimized to achieve a short run time, symmetric peak shapes, minimum matrix interference, and solvent consumption. Methanol-water and acetonitrile water in various proportions $(50: 50,60: 40,70: 30$, and $80: 20, v / v)$ were tested as the mobile phase on three Thermo Scientific analytical columns, namely, BDS Hypersil C18 (50 mm $\times 4.6 \mathrm{~mm}$, $5.0 \mu \mathrm{m})$, Hypurity C8 $(50 \mathrm{~mm} \times 4.6 \mathrm{~mm}, 5.0 \mu \mathrm{m})$, and Hypurity C18 $(50 \mathrm{~mm} \times 4.6 \mathrm{~mm}, 5.0 \mu \mathrm{m})$. It was observed that the ionization of RIZ and IS was augmented by addition of an acidic additive in the mobile phase. Thus, formic acid $(0.01-0.005 \%)$ and ATFA $(1-5 \mathrm{mM})$ were tried to improve the response. Although the response was comparable in both the modifiers, the peak shape of RIZ and IS was more superior in ATFA than formic acid. The effect of flow rate was also studied from 0.3 to $0.6 \mathrm{~mL} / \mathrm{min}$, which was also responsible for acceptable chromatographic peak shapes. It was found that a mixture of methanol: deionized water: $1.0 \mathrm{M}$ ATFA solution $(60: 40: 0.1, v / v / v)$ as the mobile phase and at a flow rate of $0.35 \mathrm{~mL} / \mathrm{min}$ gave the best chromatography within $3.0 \mathrm{~min}$. The response on all three columns was comparable; however, the run time was $>3.0$ min on Hypurity C8 column. BDS Hypersil C18 offered consistent and adequate response; nevertheless, the peak shapes and retention was more superior on Hypurity C18 for all QC samples and hence was selected in the present work. This may be attributed to higher carbon loading (13\%) in Hypurity C18 compared to BDS Hypersil C18 (11\%) and Hypurity C8 (8\%) columns. The reproducibility of retention times for the analyte, expressed as $\% \mathrm{CV}$, was $\leq 0.6 \%$ for 100 injections on the same column. The maximum on-column loading (at ULOQ) of RIZ per sample injection volume was $187.5 \mathrm{pg}$. Ideally, a deuterated analogue is the first choice for internal standard, but due to its unavailability, sumatriptan which belongs to the same class of triptans and having similar structure was used as IS to minimize analytical variation due to solvent evaporation, and ionization efficiency. It had a similar chromatographic behavior and was easily eluted 


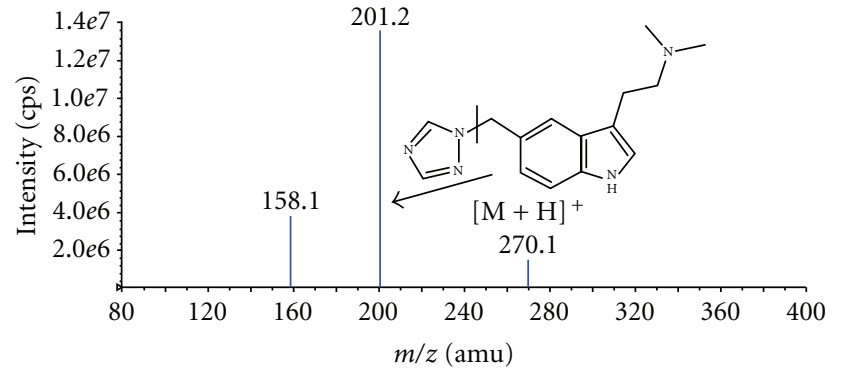

(a) Rizatriptan

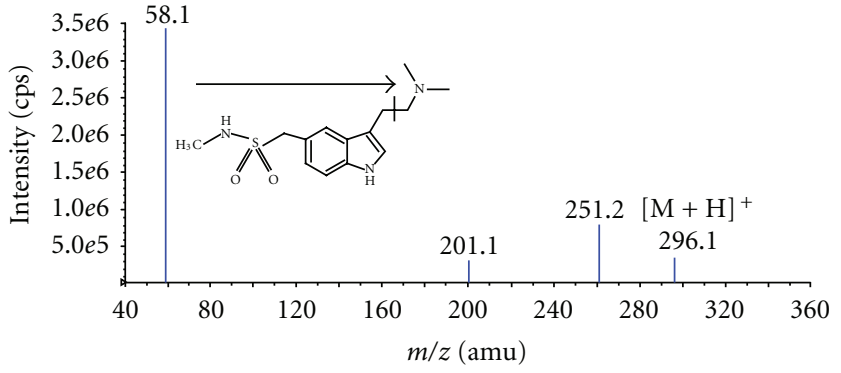

(b) Sumatriptan (IS)

Figure 1: Product ion mass spectra of (a) rizatriptan $(m / z 270.1 \rightarrow 201.2$, scan range 80-400 amu) and (b) sumatriptan $($ IS, $m / z 296.1 \rightarrow$ 58.1 , scan range $40-360 \mathrm{amu}$ ) in positive ionization mode.


(a)

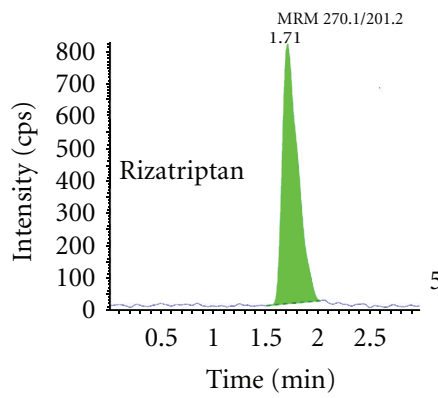

(c)

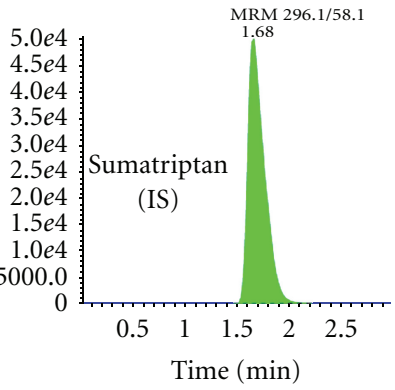



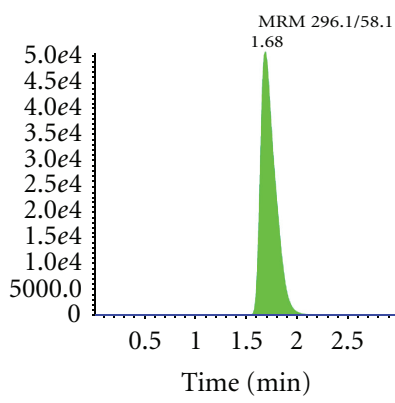

(b)
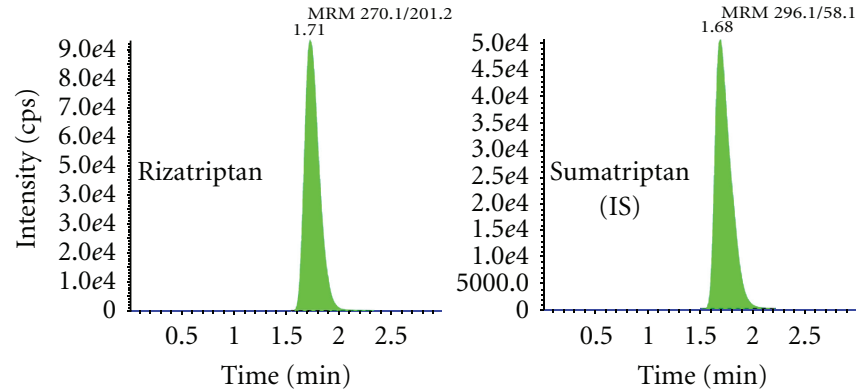

(d)

FiguRE 2: MRM ion chromatograms of rizatriptan $(m / z 270.1 \rightarrow 201.2)$ and sumatriptan $(I S, m / z 296.1 \rightarrow 58.1)$ in (a) double blank plasma (without analyte and IS), (b) blank plasma with IS, (c) rizatriptan at LLOQ and IS, and (d) real subject sample at $C_{\max }$ after administration of $10 \mathrm{mg}$ dose of rizatriptan orally disintegrating tablet.

along with the analyte. There was no effect of IS on analyte recovery, sensitivity, or ion suppression.

For sample clean-up previous reports have used liquidliquid extraction (LLE) under alkaline conditions with high recovery [11-14]. Since RIZ and IS are weakly basic compounds, the presence of relatively stronger base during LLE improves the extraction recovery [12]. Use of different basic compounds like sodium hydroxide and sodium carbonate for extraction of RIZ in solvents like methyl tert-butyl ether $[11,14]$ and ethyl acetate $[12,13]$ has been reported. In the present work, diethyl ether was used as the extraction solvents in presence of $4.5 \mathrm{M}$ ammonium hydroxide to obtain high consistent and quantitative recovery $(>78 \%)$ at all QC levels using $300 \mu \mathrm{L}$ plasma volume for processing.
3.2. System Suitability, Selectivity, Interference, and Carryover Check. During method validation, the precision $(\% \mathrm{CV})$ of system suitability test was observed in the range of 0.21 to $0.41 \%$ for the retention time and 1.35 to $2.12 \%$ for the area response of RIZ and IS. All plasma samples studied for interference at the retention time of analyte and IS were found free from any endogenous interference. Figures 2(a)-2(c) demonstrate the selectivity results with the chromatograms of double blank plasma (without IS), blank plasma (with IS), and peak response of RIZ at LLOQ concentration. No interference was observed for commonly used medications like acetaminophen, aspirin, caffeine, cetirizine, chlorpheniramine maleate, ibuprofen, and pseudoephedrine, which is evident from the real subject sample chromatograms 
TABLE 1: Intrabatch and interbatch accuracy and precision for rizatriptan.

\begin{tabular}{|c|c|c|c|c|c|c|c|c|c|}
\hline \multirow{2}{*}{ QC ID } & \multirow{2}{*}{$\begin{array}{l}\text { Conc. added } \\
(\mathrm{ng} / \mathrm{mL})\end{array}$} & \multicolumn{4}{|c|}{ Intra-batch } & \multicolumn{4}{|c|}{ Inter-batch } \\
\hline & & $n$ & $\begin{array}{l}\text { Mean conc. found } \\
(\mathrm{ng} / \mathrm{mL})^{\mathrm{a}}\end{array}$ & Accuracy (\%) & CV (\%) & $n$ & $\begin{array}{l}\text { Mean conc. found } \\
(\mathrm{ng} / \mathrm{mL})^{\mathrm{b}}\end{array}$ & Accuracy (\%) & $\mathrm{CV}(\%)$ \\
\hline LLOQ & 0.20 & 6 & 0.20 & 100.0 & 5.0 & 18 & 0.19 & 95.0 & 8.4 \\
\hline LQC & 0.60 & 6 & 0.60 & 100.0 & 2.5 & 18 & 0.58 & 96.7 & 5.0 \\
\hline MQC-2 & 5.00 & 6 & 4.74 & 94.8 & 3.8 & 18 & 4.78 & 95.6 & 2.4 \\
\hline MQC-1 & 24.00 & 6 & 22.92 & 95.5 & 2.4 & 18 & 22.76 & 94.8 & 2.0 \\
\hline HQC & 45.00 & 6 & 43.02 & 95.6 & 2.0 & 18 & 43.44 & 96.5 & 2.5 \\
\hline ULOQ & 60.00 & 6 & 56.42 & 94.0 & 4.5 & 18 & 57.25 & 95.4 & 3.1 \\
\hline
\end{tabular}

$n$ : total number of observations.

CV: coefficient of variation.

${ }^{a}$ Mean of six replicate observations at each concentration.

${ }^{b}$ Mean of eighteen replicate observations over three different analytical runs.

TABLE 2: Absolute matrix effect, relative recovery, and process efficiency for rizatriptan.

\begin{tabular}{|c|c|c|c|c|c|}
\hline $\mathrm{A}(\% \mathrm{CV})$ & $\mathrm{B}(\% \mathrm{CV})$ & $\mathrm{C}(\% \mathrm{CV})$ & $\begin{array}{l}\text { Absolute matrix effect } \\
(\mathrm{B} / \mathrm{A} \times 100)\end{array}$ & $\begin{array}{l}\text { Relative recovery } \\
(\mathrm{C} / \mathrm{B} \times 100)\end{array}$ & $\begin{array}{l}\text { Process efficiency } \\
(\mathrm{C} / \mathrm{A} \times 100)\end{array}$ \\
\hline \multicolumn{6}{|c|}{ LQC } \\
\hline $33412(2.35)$ & $32376(3.44)$ & $25856(7.82)$ & $96.9(95.8)^{*}$ & $79.9(80.6)^{*}$ & $77.4(77.2)^{*}$ \\
\hline \multicolumn{6}{|c|}{ MQC-2 } \\
\hline $270010(6.14)$ & $260020(4.01)$ & $205127(7.20)$ & $96.3(96.2)^{*}$ & $78.9(79.1)^{*}$ & $76.0(76.1)^{*}$ \\
\hline \multicolumn{6}{|c|}{ MQC-1 } \\
\hline $1250559(6.89)$ & $1198036(4.58)$ & $1026817(8.50)$ & $95.8(98.0)^{*}$ & $85.7(79.2)^{*}$ & $82.1(77.6)^{*}$ \\
\hline \multicolumn{6}{|c|}{ HQC } \\
\hline $2485238(5.21)$ & $2368432(1.93)$ & $1978173(7.36)$ & $95.3(97.3)^{*}$ & $83.5(80.9)^{*}$ & $79.6(78.7)^{*}$ \\
\hline
\end{tabular}

A: mean area response of six replicate samples prepared in mobile phase (neat samples).

B: mean area response of six replicate samples prepared by spiking in extracted blank plasma.

C: mean area response of six replicate samples prepared by spiking before extraction.

CV: coefficient of variation.

*Values for internal standard, sumatriptan.

of RIZ at $C_{\max }$ after oral administration of $10 \mathrm{mg}$ orally disintegrating tablet formulation (Figure 2(d)). Under the optimized experimental conditions, the retention time for naratriptan and zolmitriptan was observed at 1.66 and $1.78 \mathrm{~min}$, respectively. However, due to their different MRM transitions there was no interference in the quantification of RIZ. The \% accuracy results for RIZ at both the QC levels were within 95.3 to $102.5 \%$. Carryover evaluation was performed to ensure that it does not affect the accuracy and precision of the proposed method. Almost negligible area (less than $0.42 \%$ of LLOQ area) was observed in double blank plasma run after ULOQ, which suggests no carryover of the analyte in subsequent runs.

3.3. Linearity, Sensitivity, Accuracy, and Precision. All five calibration curves were linear over the concentration range of $0.20-60.00 \mathrm{ng} / \mathrm{mL}$ with correlation coefficient $r \geq 0.9997$. A straightline fit was made through the data points by least square regression analysis to give the mean linear equation $y=(0.0801 \pm 0.0043) x+(0.0018 \pm 0.0018)$, where $y$ is the peak area ratio of the analyte/IS and $x$ the concentration of the analyte. The accuracy and precision (\%CV) observed for the calibration curve standards ranged from 97.5 to $102.3 \%$ and 0.7 to $4.1 \%$, respectively. The lowest concentration
(LLOQ) in the standard curve that can be measured with acceptable accuracy and precision was $0.20 \mathrm{ng} / \mathrm{mL}$ at a signalto-noise ratio $(\mathrm{S} / \mathrm{N}) \geq 38$ and LOD of $0.04 \mathrm{ng} / \mathrm{mL}$ at $\mathrm{S} / \mathrm{N} \geq$ 5. Based on the response it was possible to lower the LLOQ by fourfold; however, it was not required based on subject sample analysis results. Mogili et al. [14] have achieved an LLOQ of $0.1 \mathrm{ng} / \mathrm{mL}$ with $\mathrm{S} / \mathrm{N}$ above 12 , while the LOD was $0.0125 \mathrm{ng} / \mathrm{mL}$ at $\mathrm{S} / \mathrm{N}>3$.

The intra-batch and inter-batch precision and accuracy were established from validation runs performed at six QC levels (Table 1). The intra-batch precision (\%CV) ranged from 2.0 to 5.0 and the accuracy was within 94.0 to $100.0 \%$. For the inter-batch experiments, the precision varied from 2.0 to 8.4 and the accuracy was within 94.8 to $96.7 \%$.

3.4. Recovery, Matrix Effect, Matrix Factor, and Ion Suppression. The relative recovery, absolute matrix effect, and process efficiency data for RIZ are presented in Table 2. The relative recovery of the analyte is the "true recovery," which is unaffected by the matrix as it is calculated by comparing the area ratio response (analyte/IS) of extracted (spiked before extraction) and unextracted (spiked after extraction) samples. The mean relative recovery obtained for RIZ and IS was $>78 \%$. The relative matrix effect which compares 
TABLE 3: Stability results for rizatriptan under different conditions.

\begin{tabular}{|c|c|c|c|c|c|}
\hline Stability & Storage condition & Level & $\begin{array}{c}\text { Mean stability sample }{ }^{\mathrm{a}} \\
(\mathrm{ng} / \mathrm{mL})\end{array}$ & $\% \mathrm{CV}$ & $\%$ change \\
\hline \multirow{2}{*}{ Bench top stability } & \multirow{2}{*}{ Room temperature ( $24 \mathrm{~h}$ ) } & LQC & 0.57 & 1.6 & -5.0 \\
\hline & & HQC & 45.19 & 1.9 & 0.4 \\
\hline \multirow{2}{*}{$\begin{array}{l}\text { Processed sample stability } \\
\text { (extracted samples) }\end{array}$} & \multirow{2}{*}{ Auto sampler $\left(4^{\circ} \mathrm{C}, 72 \mathrm{~h}\right)$} & LQC & 0.59 & 1.9 & -1.7 \\
\hline & & HQC & 41.70 & 1.8 & -7.3 \\
\hline \multirow{2}{*}{$\begin{array}{l}\text { Processed sample stability } \\
\text { (extracted samples) }\end{array}$} & \multirow{2}{*}{ Room temperature (72 h) } & LQC & 0.58 & 2.9 & -3.3 \\
\hline & & HQC & 42.13 & 2.3 & -6.4 \\
\hline \multirow{2}{*}{ Freeze and thaw stability } & \multirow{2}{*}{ After 6 th cycle at $-20^{\circ} \mathrm{C}$} & LQC & 0.56 & 3.8 & -6.7 \\
\hline & & HQC & 45.39 & 2.7 & 0.9 \\
\hline \multirow{2}{*}{ Long-term stability } & \multirow{2}{*}{79 days at $-20^{\circ} \mathrm{C}$} & LQC & 0.60 & 2.2 & 0.0 \\
\hline & & HQC & 45.50 & 1.5 & 1.1 \\
\hline
\end{tabular}

$\%$ Change $=(($ Mean stability samples - Mean comparison samples $) /$ Mean comparison samples $) \times 100$ LQC: low-quality control; HQC: high-quality control; CV: coefficient of variation.

${ }^{\mathrm{a}}$ Mean of six replicates at each level.

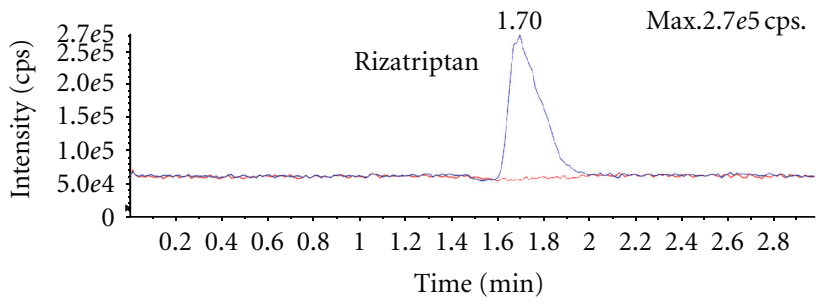

(a) XIC of +MRM (2 pairs): 270.1/201.2 amu

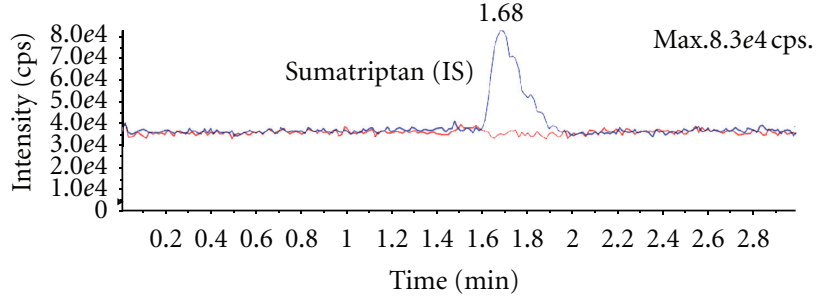

(b) XIC of +MRM (2 pairs): 296.1/58.1 amu

FIGURE 3: Representative postcolumn analyte infusion MRM LC-MS/MS overlaid chromatograms for rizatriptan and sumatriptan. (a) Exact ion current (XIC) chromatogram of rizatriptan $(\mathrm{m} / z 270.1 \rightarrow 201.2)$; (b) XIC of sumatriptan $($ IS, $m / z 296.1 \rightarrow 58.1)$.

the precision (\%CV) values between different lots (sources) of plasma (spiked after extraction) samples varied from 0.5 to 4.6 for RIZ at the LQC and HQC levels. Results of postcolumn analyte infusion experiment in Figure 3 indicate no ion suppression or enhancement at the retention time of RIZ and IS. The average matrix factor value calculated as the response of postspiked sample/response of neat solution (in mobile phase) at the LLOQ level was 0.95 , which indicates a minor suppression of about $5 \%$.

3.5. Stability and Dilution Integrity. Stability experiments were performed to evaluate the analyte stability in stocks solutions and in plasma samples under different conditions, simulating the same conditions which occurred during study sample analysis. The stock solution of RIZ was stable at room temperature for $6 \mathrm{~h}$ and at $4{ }^{\circ} \mathrm{C}$ for 21 days. The intermediate stock solution of RIZ in methanol-deionized water $(50: 50, v / v)$ was stable at $4^{\circ} \mathrm{C}$ for 19 days with $\%$ change of 0.2 . RIZ was found stable in controlled plasma at room temperature up to $24 \mathrm{~h}$ and for six freeze and thaw cycles. The analyte in extracted plasma samples was stable for $72 \mathrm{~h}$ under refrigerated conditions $\left(4^{\circ} \mathrm{C}\right)$ and for $72 \mathrm{~h}$ under room temperature. The spiked plasma samples of RIZ stored at $-20^{\circ} \mathrm{C}$ for long-term stability were found stable for minimum period of 79 days. The values for the percent change for all the stability experiments are compiled in Table 3 .
The precision values for dilution integrity of $1 / 10$ of $5 \times \operatorname{ULOQ}(30.00 \mathrm{ng} / \mathrm{mL})$ and $1 / 10$ of HQC $(4.50 \mathrm{ng} / \mathrm{mL})$ concentration were 2.2 and $2.4 \%$, respectively, while the accuracy results were within 97.3 and 101.7, which is within the acceptance limit of $15 \%$ for precision (\% CV) and 85 to $115 \%$ for accuracy.

3.6. Application of the Method in Human Subjects and Incurred Sample Reanalysis. The validated method was applied to a bioequivalence study of $10 \mathrm{mg}$ test and reference formulations of RIZ in 40 and 32 healthy Indian male subjects under fasting and fed conditions, respectively. The mean pharmacokinetic profile for the treatment, under fasting condition and fed condition, is presented in Figures 4(a) and 4(b), respectively. In all approximately 4900 samples including the calibration, QC and volunteer samples were run and analyzed successfully. The mean pharmacokinetic parameters obtained for the test and reference formulation for both the studies are presented in Table 4(a). As evident from these values, there was no significant effect of food on the pharmacokinetic parameters. In healthy volunteers, food increases the area under the curve (AUC) by about $20 \%$ and delays absorption of RIZ; however, there is no significant effect on $C_{\max }$ and $T_{\max }$ values [22]. In the present work the increase in AUC values was only about $5 \%$, which can be attributed to genetic difference, race, age, gender (body size and muscle mass), type of food, and so forth. The mean 
TABLE 4: (a) Mean pharmacokinetic parameters after oral administration of $10 \mathrm{mg}$ rizatriptan orally disintegrating tablet formulation to 40 and 32 healthy Indian subjects under fasting and fed conditions, respectively. (b) Comparison of treatment ratios and $90 \%$ CIs of natural log- (Ln-) transformed parameters for test and reference $10 \mathrm{mg}$ orally disintegrating tablet formulations of rizatriptan in 40 and 32 healthy Indian subjects under fasting and fed conditions, respectively.

(a)

\begin{tabular}{lcccc}
\hline & & Fasting & & Fed \\
Parameter & Test & Reference & Test & Reference \\
& Mean $\pm \mathrm{SD}$ & Mean $\pm \mathrm{SD}$ & Mean $\pm \mathrm{SD}$ & $\mathrm{Mean} \pm \mathrm{SD}$ \\
\hline$C_{\max }(\mathrm{ng} / \mathrm{mL})$ & $22.69 \pm 6.49$ & $21.93 \pm 5.85$ & $21.62 \pm 5.56$ & $21.10 \pm 5.63$ \\
$T_{\max }(\mathrm{h})$ & $1.51 \pm 0.69$ & $1.62 \pm 0.85$ & $2.11 \pm 0.85$ & $2.01 \pm 0.65$ \\
$t_{1 / 2}(\mathrm{~h})$ & $1.91 \pm 0.25$ & $1.90 \pm 0.26$ & $2.01 \pm 0.24$ & $2.03 \pm 0.24$ \\
$\mathrm{AUC}_{0-24 \mathrm{~h}}(\mathrm{~h} \cdot \mathrm{ng} / \mathrm{mL})$ & $88.72 \pm 22.00$ & $86.26 \pm 20.50$ & $92.69 \pm 21.00$ & $93.36 \pm 23.09$ \\
$\mathrm{AUC}_{0-\mathrm{inf}}(\mathrm{h} \cdot \mathrm{ng} / \mathrm{mL})$ & $89.56 \pm 22.09$ & $87.13 \pm 20.63$ & $93.66 \pm 21.07$ & $94.27 \pm 23.16$ \\
$K_{\mathrm{el}}(1 / \mathrm{h})$ & $0.369 \pm 0.045$ & $0.372 \pm 0.050$ & $0.351 \pm 0.046$ & $0.346 \pm 0.039$ \\
\hline
\end{tabular}

$C_{\max }$ : maximum plasma concentration; $T_{\max }$ : time point of maximum plasma concentration. $t_{1 / 2}$ : half-life of drug elimination during the terminal phase.

$\mathrm{AUC}_{0-t}$ : area under the plasma concentration-time curve from zero hour to $24 \mathrm{~h}$.

$\mathrm{AUC}_{0-\mathrm{inf}}$ : area under the plasma concentration - time curve from zero hour to infinity.

$K_{\mathrm{el}}$ : elimination rate constant; SD: standard deviation.

(b)

\begin{tabular}{|c|c|c|c|c|c|c|c|c|}
\hline \multirow{2}{*}{ Parameter } & \multicolumn{2}{|c|}{ Ratio (test/reference), \% } & \multicolumn{2}{|c|}{ 90\% CI (lower-upper) } & \multicolumn{2}{|c|}{ Power } & \multicolumn{2}{|c|}{ Intrasubject variation, $\% \mathrm{CV}$} \\
\hline & Fast & Fed & Fast & Fed & Fast & Fed & Fast & Fed \\
\hline $\operatorname{Ln} C_{\max }(\mathrm{ng} / \mathrm{mL})$ & 103.1 & 102.9 & $95.1-111.7$ & $96.3-110.0$ & 0.9974 & 0.9998 & 21.41 & 14.57 \\
\hline $\mathrm{Ln} \mathrm{AUC}_{0-24}(\mathrm{~h} \cdot \mathrm{ng} / \mathrm{mL})$ & 102.7 & 100.1 & $98.8-106.7$ & $96.6-103.7$ & 1.000 & 1.000 & 10.15 & 7.72 \\
\hline $\operatorname{Ln} \mathrm{AUC}_{0-\text { inf }}(\mathrm{h} \cdot \mathrm{ng} / \mathrm{mL})$ & 102.6 & 100.1 & $98.8-106.6$ & $96.7-103.7$ & 1.000 & 1.000 & 10.06 & 7.64 \\
\hline
\end{tabular}

CI: confidence interval; $\mathrm{CV}$ : coefficient of variation.

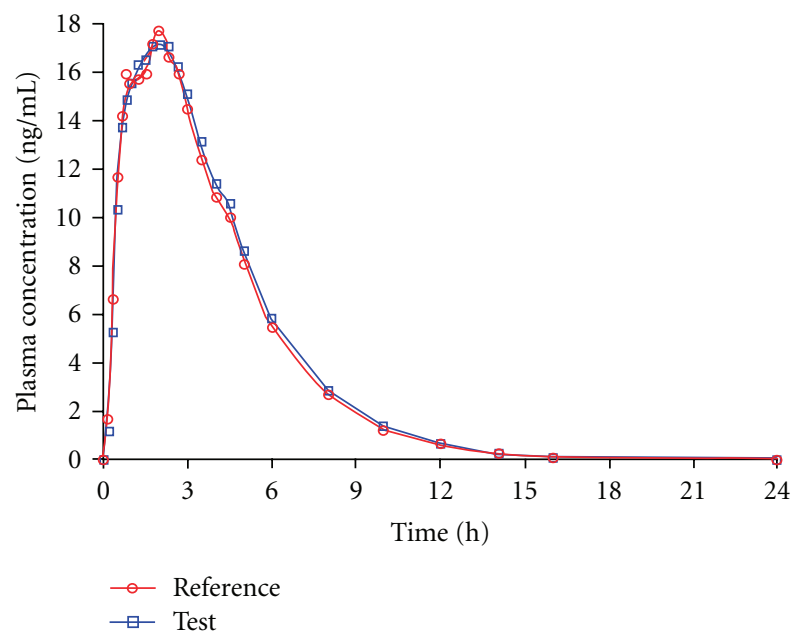

(a) Fasting

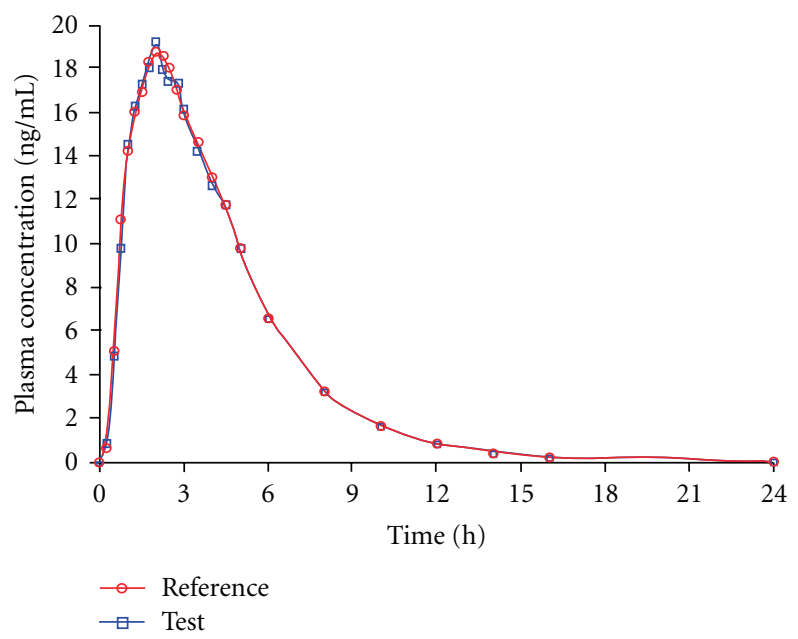

(b) Fed

FIGURE 4: Mean plasma concentration-time profile of rizatriptan after oral administration of test (10 mg rizatriptan orally disintegrating tablets of a generic company) and a reference (MAXALT-MLT, $10 \mathrm{mg}$ rizatriptan benzoate orally disintegrating tablets from Merck \& Co. Inc, Whitehouse station, NJ 08889, USA) formulation to 40 and 32 healthy subjects under fasting and fed conditions, respectively.

log-transformed ratios of the parameters and their $90 \%$ CIs were all within the defined bioequivalence range (Table 4(b)). These observations confirm the bioequivalence of the test sample with the reference product in terms of rate and extent of absorption. The \% change in the randomly selected subject samples for incurred sample reanalysis was within 11.8 to $-10.2 \%$ as shown in Figure 5. This authenticates the reproducibility of the proposed method.
3.7. Comparison with Reported Methods. Although the proposed method is not sensitive compared to few previous reports [12-14], however, the total analysis time (extraction and chromatography) is the shortest compared to many methods [9, 11, 13, 15]. Also, the on-column loading of RIZ at ULOQ was $187.5 \mathrm{pg} /$ sample injection volume. This is considerably less compared to all other procedures except [14], which helps in maintaining the efficiency and 
TABLE 5: Salient features of the present method in comparison with reported procedures for determination of rizatriptan.

\begin{tabular}{|c|c|c|c|c|c|c|c|}
\hline $\begin{array}{l}\text { Sr. } \\
\text { number }\end{array}$ & $\begin{array}{l}\text { Detection technique; } \\
\text { LLOQ }\end{array}$ & $\begin{array}{c}\text { Extraction } \\
\text { technique; } \\
\text { plasma volume } \\
\text { for processing }\end{array}$ & $\begin{array}{l}\text { Retention time; run } \\
\text { time; maximum } \\
\text { on-column loading at } \\
\text { ULOQ per injection } \\
\text { volume } \\
\end{array}$ & $\begin{array}{l}\text { Organic solvent } \\
\text { consumption } \\
\text { (extraction and } \\
\text { chromatography) } \\
\text { per sample analysis }\end{array}$ & $\begin{array}{l}\text { Postcolumn } \\
\text { infusion study; } \\
\text { relative matrix } \\
\text { effect results } \\
(\% \mathrm{CV}) \\
\end{array}$ & $\begin{array}{l}\text { Incurred } \\
\text { sample } \\
\text { reanalysis } \\
\text { results }\end{array}$ & Reference \\
\hline $1^{\mathrm{a}}$ & LC-MS/MS; $0.1 \mathrm{ng} / \mathrm{mL}$ & SPE; $1000 \mu \mathrm{L}$ & $3.3 \mathrm{~min} ; 4.0 \mathrm{~min} ; 25 \mathrm{ng}$ & $\sim 4.5 \mathrm{~mL}$ & NA & NA & [9] \\
\hline 2 & HPLC; $0.5 \mathrm{ng} / \mathrm{mL}$ & LLE; $1000 \mu \mathrm{L}$ & $5.6 \mathrm{~min} ; 10 \mathrm{~min} ; 10.0 \mathrm{ng}$ & $\sim 5.0 \mathrm{~mL}$ & NA & NA & {$[11]$} \\
\hline 3 & LC-MS/MS; $0.05 \mathrm{ng} / \mathrm{mL}$ & LLE; $100 \mu \mathrm{L}$ & $\begin{array}{l}1.039 \mathrm{~min} ; 2.0 \mathrm{~min} ; \\
2.0 \mathrm{ng}\end{array}$ & $\sim 2.5 \mathrm{~mL}$ & NA & NA & {$[12]$} \\
\hline 4 & LC-MS/MS; $0.05 \mathrm{ng} / \mathrm{mL}$ & LLE; $500 \mu \mathrm{L}$ & $\begin{array}{l}3.73 \mathrm{~min} ; 5.0 \mathrm{~min} \\
6.0 \mathrm{ng}\end{array}$ & $\sim 3.5 \mathrm{~mL}$ & NA & NA & {$[13]$} \\
\hline 5 & LC-MS/MS; 0.1 ng/mL & LLE; $100 \mu \mathrm{L}$ & $\begin{array}{c}0.94 \mathrm{~min} ; 3.0 \mathrm{~min} \\
125 \mathrm{pg}\end{array}$ & $\sim 4.0 \mathrm{~mL}$ & NA & NA & {$[14]$} \\
\hline $6^{\mathrm{b}}$ & LC-MS/MS; 0.5 ng/mL & SPE; $1000 \mu \mathrm{L}$ & $\begin{array}{l}5.1 \mathrm{~min} ; 7.0 \mathrm{~min} ; \\
6.25 \mathrm{ng}\end{array}$ & $\sim 13.0 \mathrm{~mL}$ & NA & NA & {$[15]$} \\
\hline $7^{c}$ & LC-MS/MS; $1.0 \mathrm{ng} / \mathrm{mL}$ & SPE; $1000 \mu \mathrm{L}$ & $3.48 \mathrm{~min} ; 5.0 \mathrm{~min} ; 25 \mathrm{ng}$ & $\sim 3.0 \mathrm{~mL}$ & NA & NA & {$[16]$} \\
\hline 8 & LC-MS/MS; 0.2 ng/mL & LLE; $300 \mu \mathrm{L}$ & $\begin{array}{c}1.71 \mathrm{~min} ; 3.0 \mathrm{~min} ; \\
187.5 \mathrm{pg}\end{array}$ & $\sim 5.0 \mathrm{~mL}$ & $\begin{array}{l}\text { Yes; } 0.5 \text { to } \\
4.6 \% \text { for } 8 \text { lots } \\
\text { of plasma }\end{array}$ & $\begin{array}{c}\% \text { change } \\
\text { from } 11.8 \text { to } \\
-10.2 \%\end{array}$ & PM \\
\hline
\end{tabular}

In plasma of dogs; ${ }^{\mathrm{b}}$ along with sumatriptan; ${ }^{\mathrm{c}}$ in human serum along with zolmitriptan, naratriptan, and sumatriptan; LLOQ: lower limit of quantitation; ULOQ: upper limit of quantitation; SPE: solid phase extraction; LLE: liquid-liquid extraction; NA: data not available; PM: present method.

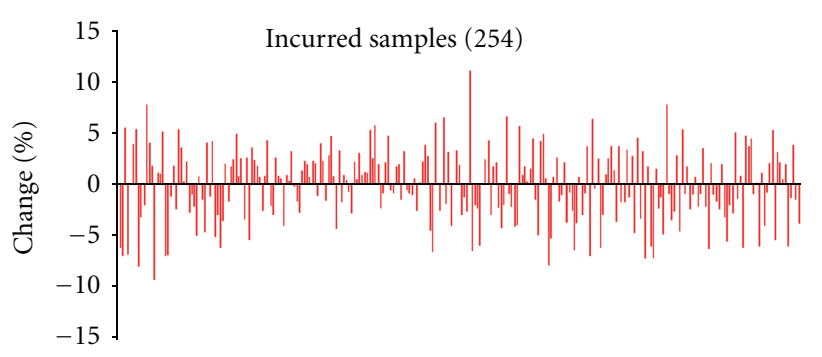

FIGURE 5: Graphical representation of results for 254 incurred samples of rizatriptan.

the lifetime of the column. Additionally, the magnitude of matrix interference has been studied by postcolumn infusion experiment and the assay reproducibility has been demonstrated by reanalysis of 254 study samples. A detailed comparison of the salient features of the present method with reported procedures for RIZ is shown in Table 5.

\section{Conclusion}

The objective of this work was to develop a selective, sensitive, rugged, and high throughput method for the estimation of RIZ in human plasma, especially to meet the requirement for subject sample analysis. The liquid-liquid extraction procedure employed in the present work gave consistent and reproducible recoveries for RIZ. The run time per sample analysis of $3.0 \mathrm{~min}$ suggests high throughput of the proposed method. The method is selective in presence of naratriptan, zolmitriptan, and other commonly used medications by healthy subjects. Moreover, the limit of quantification is low enough to monitor at least five halflives of RIZ concentration with good intra- and interassay reproducibility (\% CV) for the quality controls.

\section{Acknowledgments}

The authors are indebted to Mr. Vijay Patel, Executive Director, Cliantha Research India Ltd., Ahmedabad, for providing necessary facilities to carry out this work. The authors gratefully acknowledge Mr. Anshul Dogra, Study Director and Mrs. Arpana Prasad, R \& D Supervisor, Cliantha Research India Ltd., for their continuous support, motivation, and assistance during the course of this project.

\section{References}

[1] D. Deleu and Y. Hanssens, "Current and emerging secondgeneration triptans in acute migraine therapy: a comparative review," Journal of Clinical Pharmacology, vol. 40, no. 7, pp. 687-700, 2000.

[2] M. J. A. Láinez, "Rizatriptan in the treatment of migraine," Neuropsychiatric Disease and Treatment, vol. 2, no. 3, pp. 247$259,2006$.

[3] C. G. H. Dahlof, A. M. Rapoport, F. D. Sheftell, and C. R. Lines, "Rizatriptan in the treatment of migraine," Clinical Therapeutics, vol. 21, no. 11, pp. 1823-1836, 1999.

[4] P. J. Goadsby, "Serotonin $5-\mathrm{HT}_{1 \mathrm{~B} / 1 \mathrm{D}}$ receptor agonists in migraine: Comparative pharmacology and its therapeutic implications," CNS Drugs, vol. 10, no. 4, pp. 271-286, 1998.

[5] C. R. Shadle, G. Liu, and M. R. Goldberg, "A double-blind, placebo-controlled evaluation of the effect of oral doses of rizatriptan $10 \mathrm{mg}$ on oral contraceptive pharmacokinetics in healthy female volunteers," Journal of Clinical Pharmacology, vol. 40, no. 3, pp. 309-315, 2000.

[6] S. K. Swan, H. Alcorn, A. Rodgers et al., "Pharmacokinetic profile of rizatriptan $10-\mathrm{mg}$ tablet and $10-\mathrm{mg}$ orally disintegrating tablet administered with or without water in healthy subjects: an open-label, randomized, single-dose, 3-period crossover study," Journal of Clinical Pharmacology, vol. 46, no. 2, pp. 172-178, 2006. 
[7] M. R. Goldberg, Y. Lee, K. P. Vyas et al., "Rizatriptan, a novel 5- $\mathrm{HT}_{1 \mathrm{~B} / 1 \mathrm{D}}$ agonist for migraine: single- and multiple-dose tolerability and pharmacokinetics in healthy subjects," Journal of Clinical Pharmacology, vol. 40, no. 1, pp. 74-83, 2000.

[8] S. J. Tepper and R. C. Spears, "Acute treatment of migraine," Neurologic Clinics, vol. 27, no. 2, pp. 417-427, 2009.

[9] A. Barrish, T. V. Olah, G. J. Gatto, K. B. Michel, M. R. Dobrinska, and J. D. Gilbert, "The use of stable isotope labeling and liquid chromatography/tandem mass spectrometry techniques to study the pharmacokinetics and bioavailability of the antimigraine drug, MK-0462 (rizatriptan) in dogs," Rapid Communications in Mass Spectrometry, vol. 10, pp. 1033-1037, 1996.

[10] K. P. Vyas, R. A. Halpin, L. A. Geer et al., "Disposition and pharmacokinetics of the antimigraine drug, rizatriptan, in humans," Drug Metabolism and Disposition, vol. 28, no. 1, pp. 89-95, 2000.

[11] J. Chen, X. Jiang, W. Jiang, N. Mei, X. Gao, and Q. Zhang, "Liquid chromatographic method for the determination of rizatriptan in human plasma," Journal of Chromatography B, vol. 805, no. 1, pp. 169-173, 2004.

[12] Y. Chen, H. Miao, M. Lin et al., "Development and validation of a selective and robust LC-MS/MS method for highthroughput quantifying rizatriptan in small plasma samples: application to a clinical pharmacokinetic study," Journal of Chromatography B, vol. 844, no. 2, pp. 268-277, 2006.

[13] J. F. Guo, A. J. Zhang, L. Zhao et al., "Determination of rizatriptan in human plasma by liquid chromatographiceletrospray tandem mass spectrometry: application to a pharmacokinetic study," Biomedical Chromatography, vol. 20, no. 1, pp. 61-66, 2006.

[14] R. Mogili, K. Kanala, B. R. Challa, B. R. Chandu, and C. K. Bannoth, "Determination of rizatriptan in human plasma by liquid chromatography stable isotope dilution electrospray MS-MS for application in bioequivalence study," Chromatographia, vol. 74, pp. 585-592, 2011.

[15] D. A. McLoughlin, T. V. Olah, J. D. Ellis, J. D. Gilbert, and R. A. Halpin, "Quantitation of the 5HT1D agonists MK462 and sumatriptan in plasma by liquid chromatographyatmospheric pressure chemical ionization mass spectrometry," Journal of Chromatography A, vol. 726, no. 1-2, pp. 115-124, 1996.

[16] K. Vishwanathan, M. G. Bartlett, and J. T. Stewart, "Determination of antimigraine compounds rizatriptan, zolmitriptan, naratriptan and sumatriptan in human serum by liquid chromatography/electrospray tandem mass spectrometry," Rapid Communications in Mass Spectrometry, vol. 14, pp. 168-172, 2000.

[17] Guidance for Industry, Bionanlytical Method Validation, US Department of Health and Human Services, Food and Drug Administration Centre for Drug Evaluation and Research (CDER), Centre for Veterinary Medicine (CVM), 2001.

[18] B. K. Matuszewski, M. L. Constanzer, and C. M. Chavez-Eng, "Strategies for the assessment of matrix effect in quantitative bioanalytical methods based on HPLC-MS/MS," Analytical Chemistry, vol. 75, no. 13, pp. 3019-3030, 2003.

[19] R. King, R. Bonfiglio, C. Fernandez-Metzler, C. Miller-Stein, and T. Olah, "Mechanistic investigation of ionization suppression in electrospray ionization," Journal of the American Society for Mass Spectrometry, vol. 11, no. 11, pp. 942-950, 2000.

[20] Guidance for Industry: ICH E6 Good Clinical Practice, U.S. Department of Health and Human Services, Food and Drug Administration, Centre for Drug Evaluation and Research
(CDER), Centre for Biologics Evaluation and Research (CBER), 1996.

[21] M. Yadav and P. S. Shrivastav, "Incurred sample reanalysis: a decisive tool in bioanalytical research," Bioanalysis, vol. 3, pp. 1007-1024, 2011.

[22] H. Cheng, W. J. Polvino, D. Sciberras et al., "Pharmacokinetics and food interaction of MK-462 in healthy males," Biopharmaceutics and Drug Disposition, vol. 17, pp. 17-24, 1996. 


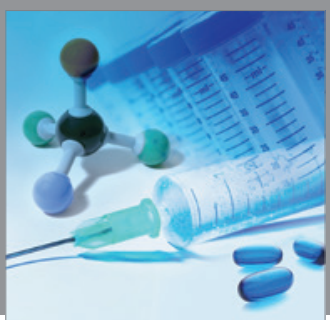

International Journal of

Medicinal Chemistry

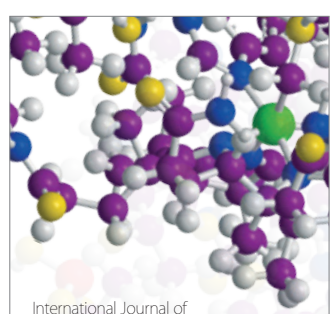

Carbohydrate Chemistry

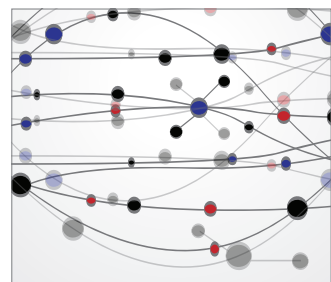

The Scientific World Journal
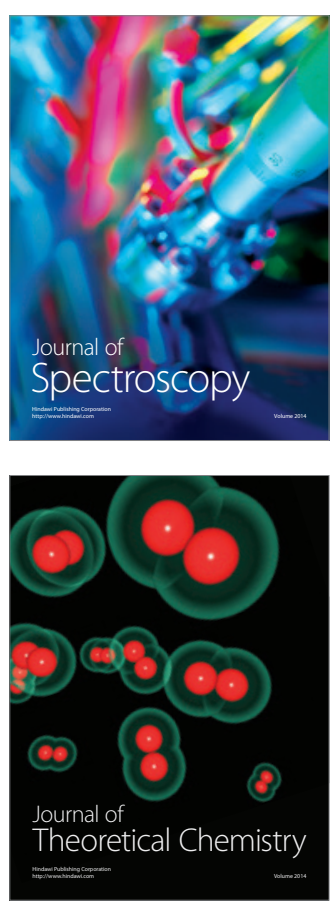
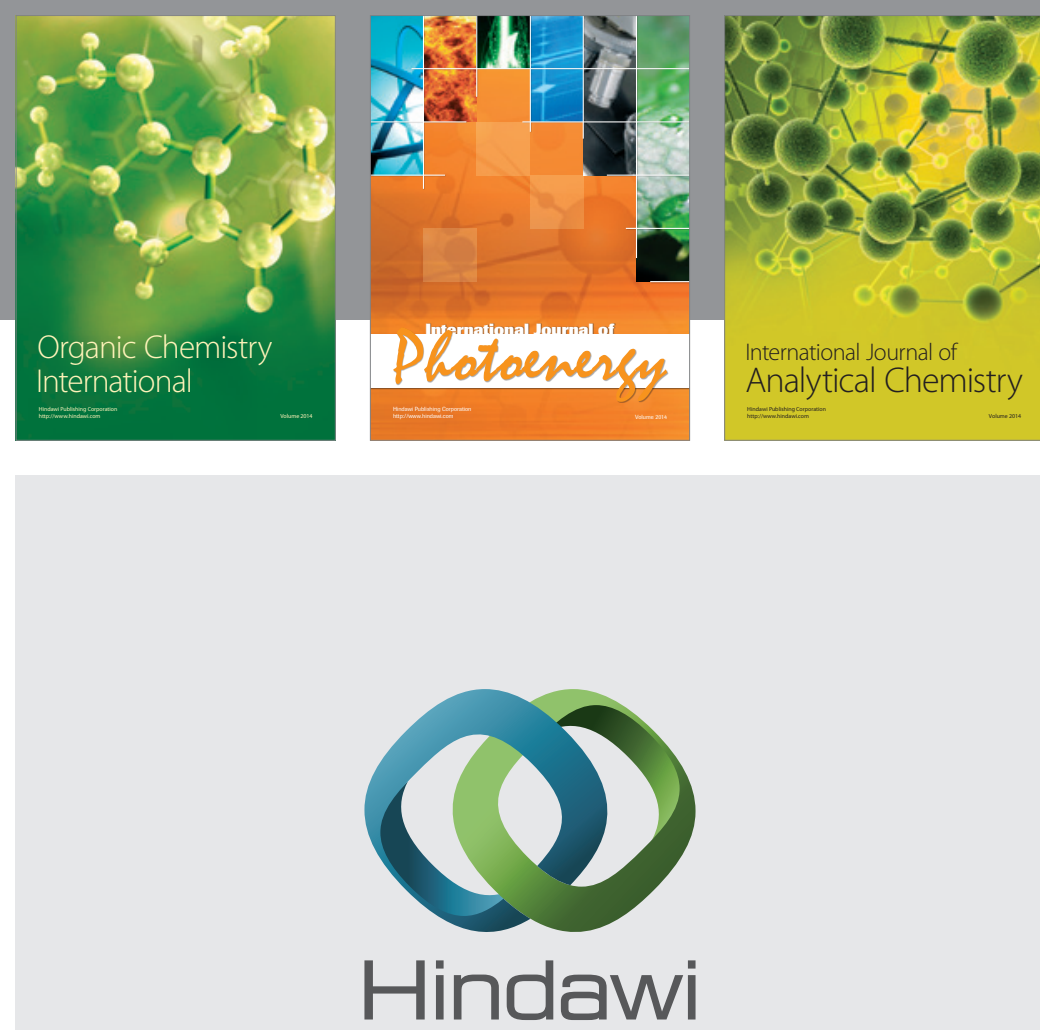

Submit your manuscripts at

http://www.hindawi.com
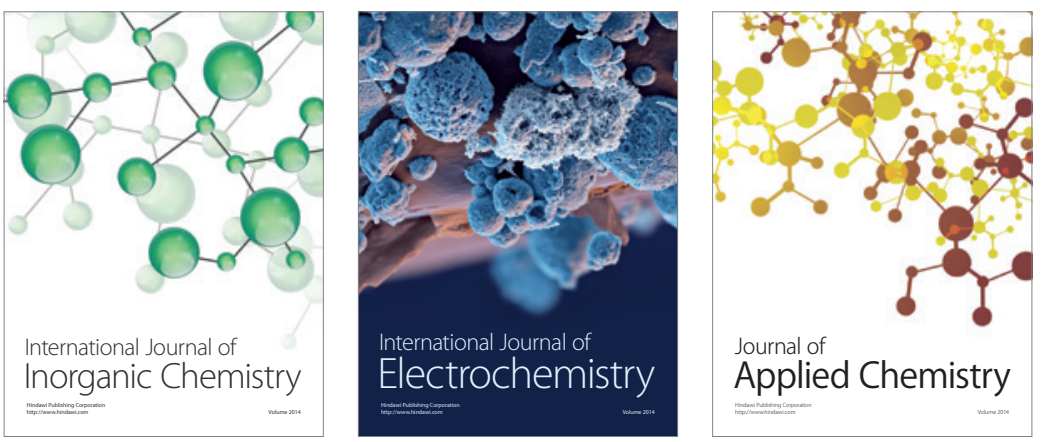

Journal of

Applied Chemistry
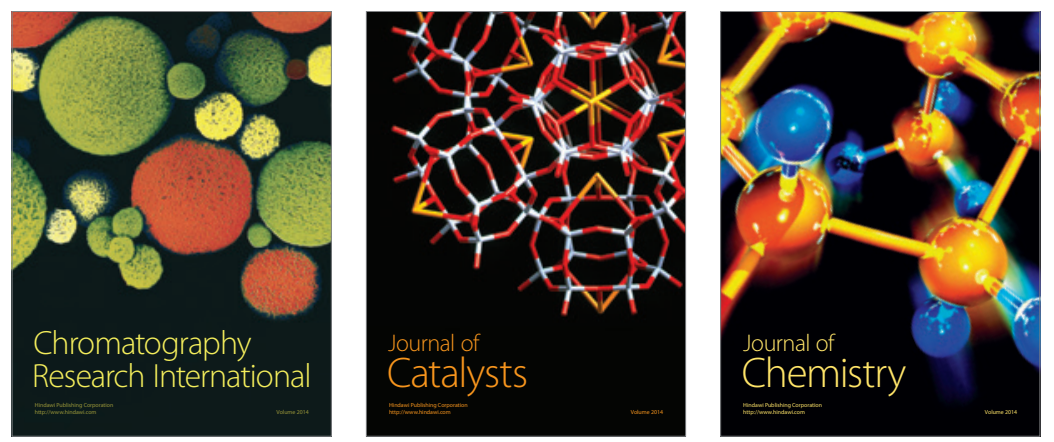
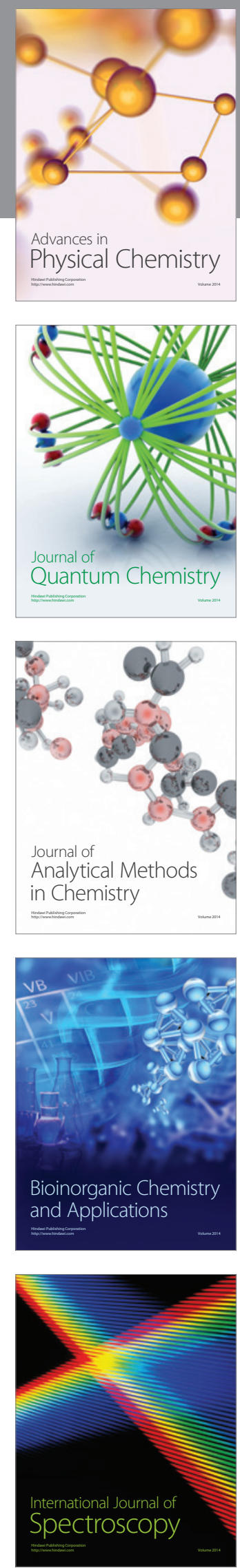